\title{
Government's role in ensuring sustainable waste management: Valencia's case from the triple bottom line perspective
}

\author{
Marina Mattera ${ }^{1, *}$, María del Pilar López-Portillo ${ }^{1}$, and Luana Gava ${ }^{1}$ \\ ${ }^{1}$ Department of Economics and Business, Universidad Europea de Madrid, Villaviciosa de Odón, 28670 Spain
}

\begin{abstract}
Creating a solid link between people, profit and planet (known as the Triple Bottom Line-TBLframework) is the key to achieving sustainable development. In recent years there has been an increasing number of studies evaluating how firms can contribute to establishing these links, in order to ensure their own sustainable growth. In addition, this framework requires the specific support of governmental institutions, who can align and link the different stakeholders in a common vision. In the context of the European Union, the case of a waste management consortium located in a particular region of Spain is analysed. Through the evaluation of its positive economic incentives initiative within the TBL framework, results show the positive impact within sustainable growth and direct alignment with the European Union's 2020 environmental objectives.
\end{abstract}

\section{Background: triple bottom line}

Business models have been defined as a framework to understand and interrelate customer relations and business processes, considering all stakeholders and the impact in elements required in order to sustain the core product or service provision.

Taking into consideration this basis point, firms should consider first and foremost creating value for its consumers and correlating (through cost analysis, investment valuation and profits) the use of resources with the degree of added value offered to a single consumer with every product or service [1].

The elements that according to Teece (2010) should be considered to evaluate value creation are: (i) choosing technologies and features to be incorporated in the product or service, (ii) determining which are the benefits that the consumer will obtain with the purchase, (iii) identifying the market segments that will be targeted with the product or service offering, (iv) ratify available revenue streams, and (v) establish mechanisms to capture value[2].

These elements can be combined in multiple different ways, with diverse strategic approaches, and each configuration will result in a unique business model. Every firm must evaluate which is the combination that suits them best.

Product or service offering then becomes key, together with the understanding how will the company derive value in terms of two major elements: people and profit. However, the production and delivery of goods and services requires the input of resources, some of which derive directly or indirectly from nature and thus the environment or planet should also be considered.
This implies that the company would see its future jeopardized if the stakeholders' needs are not met, or if the natural resources are exploited in such a way that future usage of them is compromised. Hence, it is necessary to evaluate which is the optimal combination of people, profit and planet, in order to have an effective and efficient business model that leads to a sustainable corporation.

Because of the abovementioned, three elements are essential to a sustainable business model: people, profit and planet, or the three Ps. This is known as the triple bottom line theory (TBL), which considers business models to be successful when the three Ps are combined in such a way that there is an optimal balance between them [3].

In sum, by taking into consideration at the core external social and environmental aspects of a firm's operations, companies can ensure their own success in the long run. In order to effectively achieve this, it is crucial to have a strong and accurate measuring system that portrays the overall performance of the company, including the three Ps $[4,5,6]$.

Lastly, it should be noted that academia has found TBL elements necessary to achieve sustainable development, which will in turn ensure a company's long-term consolidation and success [7]; among others).

In addition, Isaksson, Garvare and Johnson (2015) identified that the TBL requires further understanding in order to properly create these links and ensure there is a better alignment between profit and usage of resources within the planet, there is a requirement to create higher understanding within this matter.

Since humanity is currently over-exploiting natural resources in order to maintain their way of life, particularly in developed-industrialized countries and

Corresponding author: Marina.mattera@ universiadadeuropea.es 
individuals living in large cities, it becomes a crucial matter [9]. This implies that we would need 1.5 planets to provide the resources and to absorb all the waste we generate [10]. This implies that individuals, organizations and governments are not being sustainable at large.

Isaksson, Garvare and Johnson (2015) considered profit is and will continue to be a significant variable, since it plays an important role in economic growth. However, its importance should be considered in conjunction with the means to achieve it, together with stakeholders' needs and their expectations. The authors evaluated the stakeholders involved, each of their needs and which should be a theoretical global process which provides wellbeing for humanity while preserving the natural resources, as depicted in Figure 1.

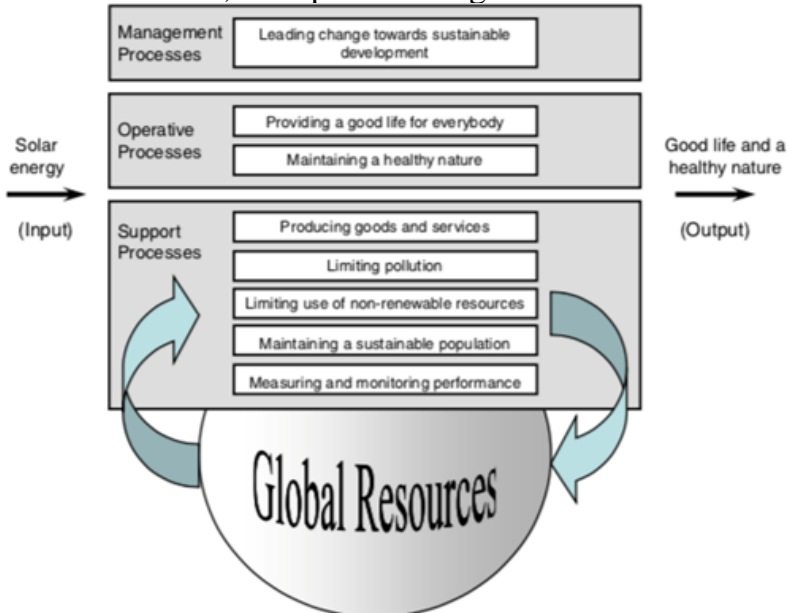

Fig. 1. The global process of providing a good life for everybody while maintaining a healthy nature

Source: Isaksson, Garvare and Johnson (2015, p.342)

\section{Global commitments and the EU's initiative}

During the past few decades, there has been an increasing concern regarding the future of the planet's natural resources and human usage of them [11]. It has been evidenced that modern civilization has been consuming the available non-renewable resources which can jeopardize the availability of them for future generations.

In addition, pollution (considering all of its shapes and forms), improper disposal of waste and lack of attention to a circular economy, are attempting against the wellbeing of citizens.

Because of the above mentioned, global leaders have come to diverse agreements, including the Kyoto Protocol [12], the Burtland Report [13] among others.

The European Union's agencies, together with its country member's leaders, have consistently committed to an improvement of the resources' usage, while contributing to an amelioration of the damage caused to them. Furthermore, through specific programmes they have supported the advancement of research and development to improve production processes and citizen's day to day lives in order to minimize negative impact in the environment
One of its latest programmes (EAP, n.a.), which will end in 2020, is the $7^{\text {th }}$ Environmental Action Programme (EAP) which has as aims to:

1. "To protect, conserve and enhance the Union's natural capital

2. To turn the Union into a resource-efficient, green and competitive low-carbon economy

3. To safeguard the Union's citizens from environment-related pressures and risks to health and wellbeing

4. To maximize the benefits of the Union's environment legislation by improving implementation

5. To increase knowledge about the environment and widen the evidence base for policy

6. To secure investment for environment and climate policy and account for the environment costs of any societal activities

7. To better integrate environmental concerns into other policy areas and ensure coherence when creating new policy

8. To make the Union's cities more sustainable

9. To help the Union address international environmental and climate challenges more effectively" (EAP, n.a.)

These objectives have guided the strategies, plans and actions carried out by the EU and its various organizations, as well as funding projects that combine diverse stakeholders aiming at tackling some of these goals.

Because of this, the collaboration between sectors, and the higher impact of the service sector in a knowledge-based economy will be key elements in achieving a sustainable future where the people, planet and profit are all balanced and taken into consideration.

In order to achieve these objectives, one of the alternatives is the generation of resources. The Spanish government, aligned with the EU, has a strong commitment to the circular economy, where the elements can be reused, revalued or recycled, thus closing the loop and properly managed waste.

Companies should re-design their products as well as their productive processes in order to turn them into more sustainable ones, incorporating recycled materials, reusing others, while reducing their $\mathrm{CO} 2$ emissions and improving the usage of renewable energies.

Meanwhile, there is a need for greater consumer awareness, which tackles from purchasing choices to waste disposal. By having more conscious consumers that act in a sustainable manner, firm's actions can be complemented as well as setting new trends within the market.

Public entities, and governmental policy at large, has a fundamental role in regulating or arbitrating the "playing field" to ensure a circular economy. By introducing the right policies, incentives and action plans, it can contribute to a win-win situation for citizens, business and the environment, hence virtuous cycle can be created through the outreach of government.

Based on the TBL theory and the EU guidelines, the present case study tackles the question: how can 
government create specific actions that contribute to the creation of people, profit and planet virtuous cycles?

Through a case study, the empirical evidenced will be analyzed. In particular, the case of Valencia in Spain will be assessed in the particular aspect of citizen's waste management system. By evaluating this initiative, the question will be answered with specific actions undertaken and the impact in each of the TBL elements. This will be our contribution.

\section{Valencia's case from the triple bottom line perspective}

It was previously mentioned that sustainable economic growth requires a balance between people, profit and planet. When analyzing the role of government in ensuring the baseline for firms to act, it is important to focus on the areas that have the largest need for public support.

Such is the case of waste management, which requires a global understanding of activities and citizen's behaviors, while it is most likely managed by public institutions. In the case of Valencia, as it happens with other regions and countries, there organization is under a consortium of districts, to collect and manage waste.

In the case of inner Valencia ("Valencia Interior" in Spanish), this consortium serves 61 districts and over 250,000 inhabitants. By catering to this specific collective group, the system can have a higher degree of efficiency compared to each district having its own management system, as well as reducing the costs associated with all the activities.

The consortium is financed directly by waste management taxes paid by the citizens, and in doing so, the effective cost of the service provided is distributed between all the neighbors of the area. The taxation percentages applied are defined according to specific criteria.

Considering this scenario, as in Spain it is cheaper to have a single dumpster instead of an entire recycling program, doing things "right" is actually more expensive in the short run than doing them "wrong". This implies that citizens in the present pay for a waste management system through their taxes yet if it did not exist, they would be saving money and simplifying their own waste disposal at home (not having to separate items).

However, as the TBL framework determines, sustainability can be ensured when there is a proper balance between the three Ps. In this context, even though today citizens may not view the negative effects, the future impact has been clearly defined by science as a strong imbalance towards the planet that will in turn affect people and profit.

With a great understanding of this situation, the consortium of Inner Valencia opted to modify the incentives offered to citizens, as an economic tool to impact their behavior. In doing so, incentives can be positive or negative instruments [14], being the first type the ones implemented by the Spanish entity.
This implies there is a positive reward for a specific positive environmental behavior, being directly applied to consumers in their home environments, instead of enterprises. By taking this initiative, the government is on the one hand contributing to a greater awareness campaign, and on the other hand, reducing the negative impact on the environment of not separating waste and all elements being thrown in a dumpster.

Waste management has three sections: collection, selection (waste separation) and treatment; since citizens cannot directly influence the third one, the positive reward directly affects the first two. In doing so, citizens bring their pre-separated items to the consortium's facilities, and if they have been properly segregated, the items are weighted and points are awarded to the person.

The consortium is directly impacted by the measure as with proper disposal there is a lower requirement of public investment in collection or selection, being able to redistribute some of the resources invested into improving treatment. By doing so, the system becomes more efficient.

From the users' perspective, points are accumulated over a period, with a maximum points per category and per day. For instance, there are máximum quantities per user, per type of waste or per day (in a single day a user can bring max. $50 \mathrm{~kg}$ of furniture, any additional $\mathrm{kg}$ would not result in an increase in points, which would be 25 for this type of residue). Additionally, some contributions do not have specific incentives, and all are accumulated in a specific card called "My environmental account" ( "Mi cuenta ambiental" in Spanish) [15].

This results in a direct economic benefit for the citizen because the waste disposal tax he/she will have to pay will be lower compared to other inhabitants of the districts who do not participate in the program. Figure 2 represents the flow herein described.

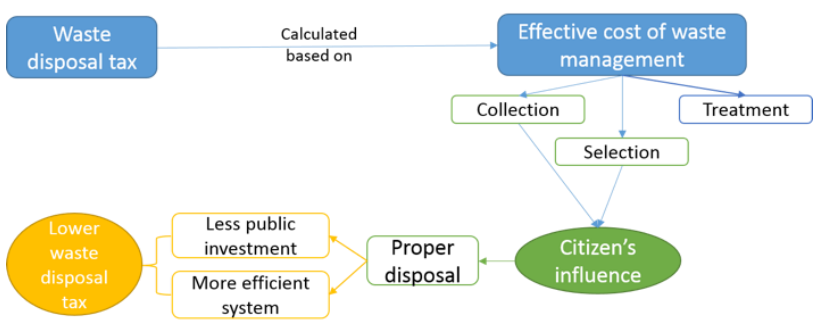

Fig. 2. Waste disposal tax and effective waste management Source: Own elaboration

From the moment the programme was introduced, citizens were interested in participating and the number of users registered has been increasing ever since. In Figure 3, the evolution of the number of users adhered to the programme has been depicted.

As a result of applying this system, the Inner Valencia consortium has evidenced citizens have benefited with up to $50 €$ reduction in the waste management tax. This creates a significant incentive and since the measure has been implemented in the past few years, there has been a positive feedback from the overall community. 
Users of "Mi Cuenta Ambiental" card

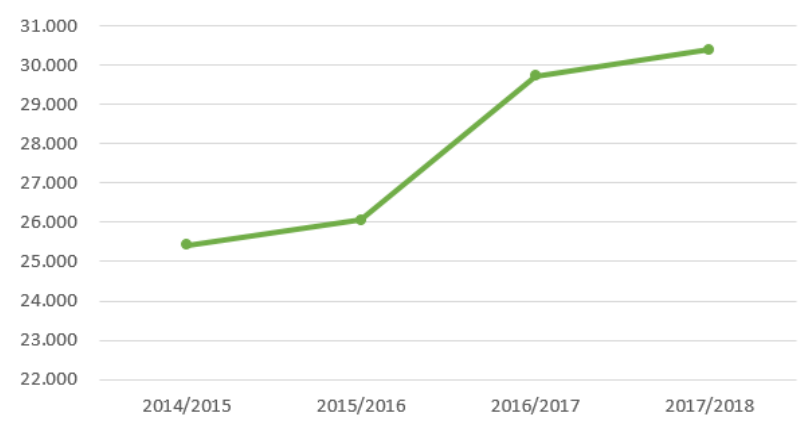

Fig. 3. Evolution of the number of users of the "Mi Cuenta Ambiental" system

Source: Inner Valencia Consortium (2019)

What is more, since the programme was implemented, the positive effect of this positive incentive has been evidenced in the quantity of $\mathrm{kg}$ disposed at the waste management collection point. Figure 4 depicts this evolution during the last years, where the total $\mathrm{kg}$ of residues collected at the waste management point has been increasing. The efficiency of the system clearly improves as citizens become more conscious of the benefits for themselves, the community and the environment.

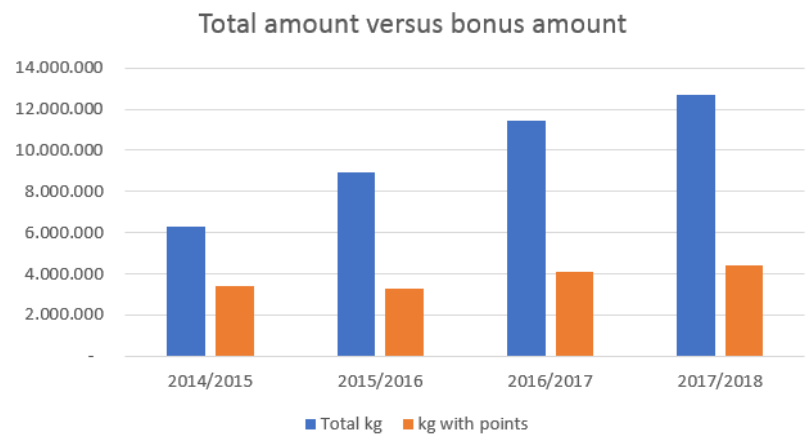

Fig. 4: Evolution of the quantity $(\mathrm{kg})$ of residues collected at the waste management point associated to the programme.

Source: Inner Valencia Consortium (2019)

\section{Conclusions, limitations and future lines of research}

Based on the TBL theory and the EU guidelines, there is a need to further understand how government can create specific actions that contribute to the creation of a virtuous cycle including people, profit and planet.

Considering the EAP 2020 program, there is a strong commitment to improve resource efficiency; increase knowledge regarding environmental issues; safeguard citizens from environment-related pressures and risks to their health and wellbeing; make the EU's citizens more sustainable; address international environmental and climate challenges more effectively; and securing investment, accounting for environmental costs of any activity.

The case herein studied of Inner Valencia's consortium directly tackles the matters described in the previous paragraph and displays a framework in which the three Ps can be balanced. This shows the government's policy, when understanding its citizens' cultural traits and behavior, can accurately create a virtuous cycle in a particular area.

Consumers participating in the program improve their own knowledge regarding waste selection and collection, understanding better the impact of their choices in the present and future. This is especially relevant when dealing with non-daily waste items, such as mattresses, furniture, electrical gadgets (phones, radio, sound systems), home appliances and electronics (washing machine, TVs, computers, etc.).

Additionally, the waste management system also targets other elements such as used oil or paint, that require a special treatment and can be incorporated into the waste management program. Citizens may not be aware of the possibilities expanding from these items, and they are not typically included in the basic recycling programs most individuals practice at home including paper, organic, plastic or glass.

By properly identifying the alternatives to dispose those items that have a more difficult treatment process, simplifying the selection and collection improves the waste management. The re-orientation of resources to possible reusing, revaluing or recycling (depending on each case) of materials or entire elements contributes significantly to a more efficient waste management system that will affect the local community in the medium and long term.

As it was abovementioned, the improved efficiency and re-orientation of resources are direct "profits" that can be accounted for in the case of a TBL government approach instead of a corporate one. When discussing positive impact in a government, the "profit" can be an increase of efficiency in the usage of resources. Firstly, between 2014-2018 period, it was evidenced that the amount of waste disposed at the collecting point directly by citizens doubled, as well as reflecting a $20 \%$ increase in the amount of families that subscribed to the program since its introduction of the initiative $\mathrm{e}^{\mathrm{a}}$.

In addition to the abovementioned, the initiative has contributed to a specific profit for the governmental organization behind the consortium, by ensuring higher efficiency and data management, which enabled its participation in a European Union R\&D funded project under the H2020 programme, named URBANREC. This directly affects the consortium by increasing the funding obtained to carry out diverse initiatives including new approaches for the valorization of urban waste [16].

Considering the experience derived from Inner Valencia Consortium, it can be concluded that in order to directly impact the creation of a virtuous cycle including people, profit and planet, public institutions (i.e. government) should implement strategies that directly tackle:

\footnotetext{
a Information provided directly by the authorities of the Inner Valencia Consortium.
} 
- consumers' economic benefit, to reward citizens for their efforts and commitment with the region's future;

- improving waste management efficiency, reducing the cost for citizens and enabling investments to be devoted to other wastemanagement related activities;

- environmental protection, as elements not properly disposed can end up in dumpsters or other areas, polluting common resources such as aquifers;

- trend setting, creating new status quo with regards to waste management in the region.

In addition to how government can create specific actions that contribute to the creation of a virtuous TBL cycle, these strategies indirectly impact the EAP 2020 objectives by improving the awareness of environmental issues, securing investment and accounting for environmental costs of any activity, and safeguard citizens from environment-related pressures and risks to their health and wellbeing, which can also be derived from improper waste disposal.

Furthermore, in terms of social values, the direct benefits derived from an improved waste management system are numerous. Firstly, it encourages individuals to raise consciousness regarding their own behavior and impact in the rest of the community as well as the environment, improving the sense of justice.

Secondly, considering the abovementioned, there will be a greater equity in the contribution provided by each citizen towards waste management, directly correlated to their efforts. By the same token, individuals who can properly dispose their waste can benefit from lower taxes, increasing a fair distribution of the contribution, thus promoting a just system where there is an equal distribution of taxes commensurable with their efforts.

Lastly, with regards to social wellbeing, a proper environment where elements consumed can be treated according to reuse-recycle or revalue principles will create better social and environmental conditions, with lower rates of air pollution, as stated in the EAP 2020 objectives. These will be direct benefits incorporated to the "people" aspect of the TBL, complementing the "planet" and "profit" ones.

The present paper hence portrays a TBL framework applied to a governmental organization such as a waste management consortium, displaying a proper contribution to the profit of this agency, while contributing to improvements in the people and planet aspects of the TBL. This shows the interlinked essence of the theory which is applicable not only to companies, but also other type of organizations which also are held accountable and need to be profitable in order to sustain their operations and continue their contributions in the social context.

The present paper focuses on studying a particular case in order to better understand the actions that can be undertaken by governmental institutions in order to promote and help building virtuous people, profit, planet cycles.

Although it was not within the scope of this analysis, it would be interesting after a decade or two decades of the implementation of the My Environmental Account initiative to evaluate the overall TBL impact.

Furthermore, it would be of interest to complement this study by evaluating the possible expansion of this initiative to other regional consortiums, catering to cultural and economic differences. In this context, crossregional analysis of results would be of interest.

The authors would like to acknowledge the valuable contribution from the Inner Valencia Consortium (Consorcio de Valencia Interior), in particular Mr. Ángel Rodríguez for providing detailed data, together with citizen's feedback.

\section{References}

1. Magretta, J. (2002) Why Business Models Matter, Harvard Business Review, Harvard Business School.

2. Teece, D. J. (2010) Business Models, Business Strategy and Innovation. Long Range Planning, 43, 172-194.

3. Elkington, J. (1994) Towards the Sustainable Corporation: Win-Win-Win Business Strategies for Sustainable Development, California Management Review 36, Volume 2, pp 90-100.

4. Lee, S.; Geum, Y.; Lee, H and Park, Y. (2012) Dynamic and multidimensional measurement of product-service system (PSS) sustainability: a triple bottom line (TBL)-based system dynamics approach, Journal of Cleaner Production, Volume 32, pp. $173-$ 182.

5. Willard, B. (2012) The New Sustainability Advantage: seven business case benefits from a triple bottom line. New Society Publishers.

6. Milne, M.J. and Gray, R. (2013) W(h)iter Ecology? The triple bottom line, the global reporting initiative and corporate sustainability reporting, Journal of Business Ethics, Volume 118, No.1,pp. 118-113.

7. Venkatesh, G. (2010) Triple Bottom line approach to individual and global sustainability; Problems of Sustainable Development; 5 (2), 29-37.

8. Isaksson, R.B.; Garvare, R. and Johnson, M. (2015) The crippled bottom line - measuring and managing sustainability, International Journal of Productivity and Performance Management, 64(3), 334-355.

9. Frecè J. T.; Harder D. L. (2018) Organisations beyond Brundtland: A Definition of Corporate Sustainability Based on Corporate Values, Journal of Sustainable Development, Volume 11, pp. 184-193.

10. WWF (2010) Living Planet Report 2010. Information available at https://wwf.panda.org/knowledge_hub/all_publicatio ns/living planet report timeline/lpr_2010/ [last accessed August 30th 2019].

11. Sneddon, C; Howarth, R. B.; Noorgaard, R. B. (2006) Sustainable development in a post-Brundtland world. Ecological Economics. Volume 57, Issue 2, pp 253268.

12. United Nations (2008) Kyoto Protocol - Targets for the first commitment period. Information available in 
html format at: https://unfccc.int/process-andmeetings/the-kyoto-protocol/what-is-the-kyotoprotocol/kyoto-protocol-targets-for-the-firstcommitment-period [last accessed August 30 ${ }^{\text {th }} 2019$ ].

13. United Nations (1987) Report of the World Commission on Environment and Development: Our Common Future. Information available at: https://sustainabledevelopment.un.org/content/docum ents/5987our-common-future.pdf_[last accessed August 30 ${ }^{\text {th }} 2019$ ]

14. Zoboli, R. (1994). The integrated use of economic instruments in the policy of municipal solid waste. The Management of Municipal Solid Waste in Europe, Elsevier Science Publishers, Amsterdam.

15. Inner Valencia Consortium (Consorcio Valencia Interior) (2019) Mi Cuenta Ambiental. Information available in html format at: http://www.consorciovalenciainterior.com/micuenta-ambiental/ [last accessed September $20^{\text {th }} 2019$ ]

16. URBANREC (2019) New Approaches for the Valorisation of urban bulky waste into high added value recycled products. Information available in html format at: https://urbanrec-project.eu [last accessed November $\left.20^{\text {th }} 2019\right]$ 